\title{
Calibration of POCIS and PASSIL passive samplers - influence of humic acids
}

\author{
Hanna Lis, Paulina Kobylis, Piotr Stepnowski, Magda Caban \\ Department of Environmental Analysis, Faculty of Chemistry, University of Gdańsk, Wita Stwosza 63, Gdańsk, Poland \\ Corresponding author: hanna.meczykowska@phdstud.ug.edu.pl \\ DOI: $10.31708 /$ spi3.18/hlis.cns 18
}

\section{Introduction}

One of the techniques of monitoring pharmaceuticals in the aquatic environment is passive extraction. The passive sampler should be calibrated before use, which means that the values of the sampling rates (Rs) should be determined. The Rs values depends on environmental conditions, such as the presence of dissolved organic matter, in particular humic acids (Söderström, Lindberg, \& Fick, 2009). The aim of the present research was to compare the calibration process of two types of passive samplers in the presence of humic acids dissolved in water. As examples of passive samplers, commercially available polar organic chemical integrated sampler (POCIS) and PASSIL sampler (PASSIL - PASsive Sampling by lonic Liquds) (Caban, Męczykowska, \& Stepnowski, 2016) were used. In the POCIS sampler, a solid sorbent is used as the acceptor phase, whereas in PASSIL, for this purpose an ionic liquid is used ([P666$14][N(C N) 2])$.

\section{Materials and Methods}

In the calibration process a donor phase flow system and water (deionized, surface water and seawater) enriched with humic acids were used. Samplers (POCIS or PASSIL) were placed in a 15 liter flow thermostat $\left(20^{\circ} \mathrm{C}\right)$ for one week. A mixture of model water contaminants from the group of pharmaceuticals was selected as the analytical product (Table 1). Every $24 \mathrm{~h}$ one of the samplers was taken out of the donor phase and disassembled. Afterwards, the analytes were extracted using organic solvents. All samples obtained were analyzed by HPLC/DAD.

\section{Results and Discussion}

In both cases, a linear increase in the content of pharmaceuticals in the acceptor phase was observed. Higher selectivity of pharmaceuticals extraction with the PASSIL sampler was observed, compared to the POCIS sampler (Table 1).
Table 1. Sampling rates (Rs) [L/day] obtained for selected pharmaceuticals based on experiments carried out in a flow system with the use of water enriched with humic acids (2.5 $\mathrm{mg} / \mathrm{L})$, lake water $(3.3 \mathrm{mg} / \mathrm{L})$ and seawater $(1.3 \mathrm{mg} / \mathrm{L})$.

\begin{tabular}{|c|c|c|c|c|}
\hline & Conditions & $\begin{array}{c}\text { Lake } \\
\text { water } \\
\text { (HAs } 3.3 \\
\text { mg/L) }\end{array}$ & $\begin{array}{c}\text { Deionized } \\
\text { water } \\
\text { (HAs } 2.5 \\
\mathrm{mg} / \mathrm{L} \text { ) }\end{array}$ & $\begin{array}{c}\text { Marine } \\
\text { water } \\
\text { (HAs 1.3 } \\
\text { mg/L) }\end{array}$ \\
\hline \multirow{5}{*}{ POCIS } & Caffeine & 0.038 & 0.076 & 0.02 \\
\hline & Atenolol & 1.095 & n.d. & n.d. \\
\hline & Sulfamethoxazole & 0.105 & 0.113 & 0.04 \\
\hline & $\begin{array}{l}17 \alpha- \\
\text { Ethinylestradiol }\end{array}$ & 0.146 & 0.194 & 0.07 \\
\hline & Diclofenac & 0.183 & 0.09 & 0.078 \\
\hline \multirow{5}{*}{ PASSIL } & Caffeine & n.d. & n.d. & n.d. \\
\hline & Atenolol & n.d. & $\mathrm{t}<24 \mathrm{~h}$ & n.d. \\
\hline & Sulfamethoxazole & 0.138 & 0.139 & n.d \\
\hline & $\begin{array}{l}17 \alpha- \\
\text { Ethinylestradiol }\end{array}$ & $\mathrm{t}<24 \mathrm{~h}$ & $\mathrm{t}<24 \mathrm{~h}$ & 0.309 \\
\hline & Diclofenac & 0.259 & 5.789 & 0.019 \\
\hline
\end{tabular}

For example, caffeine extraction occurred only in the case of POCIS. The Rs of atenolol was impossible to calculate because of the duration of the kinetic area shorter than $24 \mathrm{~h}$ when deionized water and PASSIL was used. Similarly, in the case of $17 \alpha$-ethinylestradiol (except seawater), which is not the case for POCIS. In all POCIS and PASSIL extractions, the lowest Rs values were calculated after extraction from seawater, probably due to the high salinity/ionic strength. On the basis of a comparison of the results of the passive POCIS extraction carried out in lake water and deionized water enriched with HAs, a decrease in the Rs value in water with a higher HA content was observed. The exception is diclofenac $(\log P>4)$, which is probably the result of formation of a HAs sorption layer on the surface of the membrane impregnated with a hydrophobic ionic liquid. In the case of the PASSIL and POCIS, sulfamethoxazole was characterized by similar values of Rs. In conclusion, the content of organic matter is an important parameter for both samplers calibration and have impact into Rs values of most of tested pharmaceuticals. 


\section{Acknowledgments}

Financial support was provided by the National Science Center under grant UMO-2017/25/N/ST4/02389.

\section{References}

Caban, M., Męczykowska, H., \& Stepnowski, P. (2016). Application of the PASSIL technique for the passive sampling of exemplary polar contaminants (pharmaceuticals and phenolic derivatives) from water. Talanta, 155, 185-192.

https://doi.org/10.1016/j.talanta.2016.04.035

Söderström, H., Lindberg, R. H., \& Fick, J. (2009, January 16). Strategies for monitoring the emerging polar organic contaminants in water with emphasis on integrative passive sampling. Journal of Chromatography A. Elsevier.

https://doi.org/10.1016/j.chroma.2008.08.030 